\title{
Performance of Fuzzy Controlled Negative KY Boost Converter
}

\author{
M. Pushpavalli*, P. Abirami and K. Vasanth \\ EEE Department, Sathyabama University, Chennai, Tamil Nadu, India; \\ pushpa.murugan@gmail.com, abiram_80@yahoo.in, vasanthecek@gmail.com
}

\begin{abstract}
This paper proposes a novel closed loop control of Negative output KY boost converter using fuzzy logic. The power circuit consists of a capacitor and a diode in addition to the conventional boost converter circuit. The controller implemented the fuzzy logic to fuzzify the change in voltage with the reference voltage in order to obtain reduced output ripple, improved efficiency and fast settling time. The Proposed controller exhibits better performance than its closed loop counterparts such as PI and PID controllers. The simulation result illustrates that the output voltage ripple is reduced from $103 \mathrm{mV}$ to $3 \mathrm{mV}$ and also the settling time is improved from $30 \mathrm{~ms}$ to $15 \mathrm{~ms}$.It enhances the output power from 36 watts to 59.21 watts in load variations and 474 watts to 987 watts in line variations phenomenon. The Hardware development was also developed for the same and the performance was observed.
\end{abstract}

Keywords: Fuzzy Logic Controller, Negative KY Boost Converter, PID Controller

\section{Introduction}

Handheld electronic gadgets have been widely used in recent years. This increase in demand of these handheld electronic devices from the power supply is growing day by day. To meet the power requirement an efficient conversion technique has to be formulated in the field of electrical control engineering ${ }^{1}$. DC-DC converters are the device that effectively converts one voltage level to another with merest loss of energy. DC choppers play very vital role in many low power \& high power applications ${ }^{2}$. The frequent problems encounter in hand held devices is power management issues. There is a need for regulated output voltage from a constant power source even when there is a fluctuation during charging or discharging.

$\mathrm{KY}$ converter combined with the boost converter to enlarge the voltage ratio of the KY converter. It is Suitable for low ripple applications ${ }^{3}$. A Negative output KY boost converter, which needs one more diode and one more capacitor as compared to boost converter. It converts positive DC Voltage to negative DC Voltage. In modern years, there has been advancement of DC-DC converters by using Fuzzy Logic Controller, Neural networks, and Neuro Fuzzy Controller. Here, we have implemented the DC - DC converters using fuzzy logic controller ${ }^{3}$.

\section{Basic Working Principles of Negative Output KY Boost Converter}

The Figure 1 shows Negative KY boost converter. This converter consists of primary switch single energy carrying capacitance $C_{b}$ with single energy carrying diode $\mathrm{D}_{\mathrm{b}}$, single freewheeling diode $\mathrm{D}_{\mathrm{f}}$ single input inductance $\mathrm{L}$ and output capacitance $\mathrm{C}_{\mathrm{o}}$. Additionally, single output resistance $\mathrm{R}_{\mathrm{o}}$ denotes the output load.

Mode 1: In Figure 2, when the switch is turned on, L gets magnetized due to the input voltage $\left(\mathrm{V}_{\mathrm{i}}\right)$ across it. Also it charges the energy transferring capacitance and

${ }^{*}$ Author for correspondence 


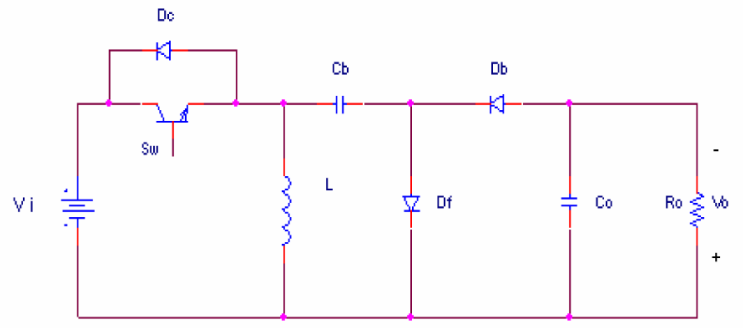

Figure 1. Negative KY Boost converter.

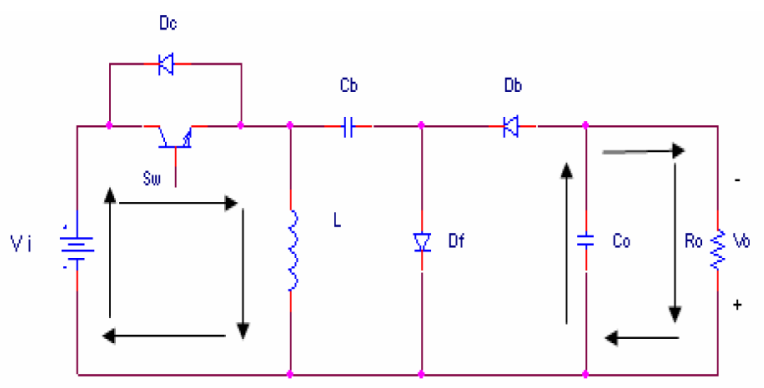

Figure 2. Mode 1 Operation.

the output capacitance supplies the energy requirement of the load. So there are three power flows in this mode. First power flows from positive terminal of the supply voltage and it flows through the switch and inductor and it returns through the neutral. Second power starts from positive terminal of the supply voltage and through the switch and energy transferring capacitance $\left(\mathrm{C}_{\mathrm{b}}\right), \mathrm{D}_{\mathrm{f}}$ and returns through the neutral. The third power flows from the output capacitance to output resistancel.

Mode 2: From Figure 3, when the Switch is turned off the voltage across $L$ is obtained from the difference between the input voltage and output voltage that exists across the energy transferring capacitance, and thus the inductor gets demagnetized. Also energy transferring capacitance gets discharged. Thus, there is only one power flow from the positive terminal of the supply voltage through $\mathrm{Db}$ through output capacitance and then $\mathrm{L}$ and the output ${ }^{1}$.

Figure 4 shows the closed output of Negative KY boost converter. The various (PI, PID \& Fuzzy) controllers are analysed in this paper. The load output voltage is sensed. Error detector compares The reference voltage and load voltage are compared by error detector in order to create error signal and it is fed to controller block. Depending upon this error signal, a control signal is given to the converter by various controllers like fuzzy, PI or PID which

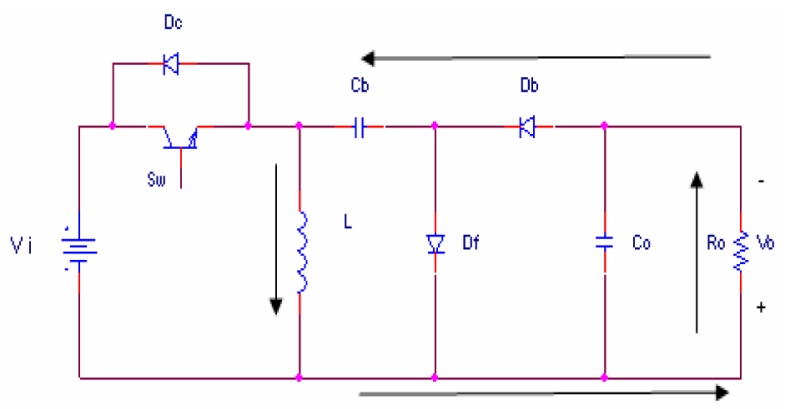

Figure 3. Mode 2 Operation.

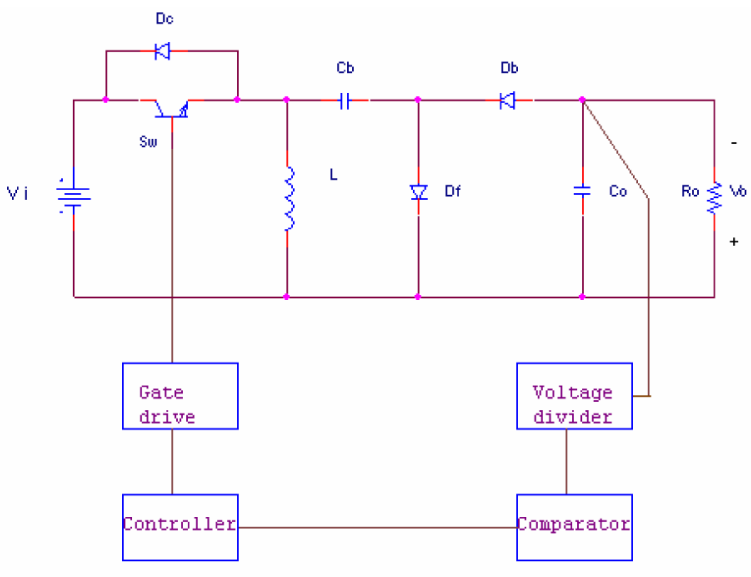

Figure 4. Block diagram for Negative KY boost converter.

in turn fine tune the switching pulse so as to control the load voltage.

In this paper the fuzzy, PI and PID controllers are compared. To tune the values of $\mathrm{Kp}, \mathrm{Ki}$ and $\mathrm{Kd}$ in a PI and PID controllers Ziegler - Nichols method is used. When comparing with all the other controllers, it is proved that the fuzzy logic controller is considered as the best one.

\section{Closed Loop Negative KY Boost Converter using PI Controller}

By giving feedback to the converter, we can improve the performance of the PI controller to overcome the disturbances. The combination of proportional and integral terms is important The PI controller is used to increase the speed of the response and also to eliminate the steady state error.

The contribution from the integral term is proportional to both the magnitude of the error and the duration of the error. The accumulated error is then multiplied by the integral gain $\left(\mathrm{K}_{\mathrm{i}}\right)$ and added to the controller output. 
The integral term accelerates the movement of the process towards set point and eliminates the residual steady-state error that occurs with a pure proportional controller. The overall controller output is given by PI Controller (proportional-integral controller) is a special case of the PID controller in which the derivative (D) of the error is not used.

The controller output is given by $\mathrm{Kp} \Delta+\mathrm{Ki} \int \Delta \mathrm{dt}$

where, $\Delta$ is the error or deviation of actual speed from the reference speed. $\Delta=\mathrm{SP}-\mathrm{PV}$

The simulink model of PI controller is shown in Figure 5 and is designed for the Negative output KY boost converter and its performances are observed by the voltage, current and power waveforms.

The output voltage and current waveforms are shown in Figure 6. The performance of the PI controller can be

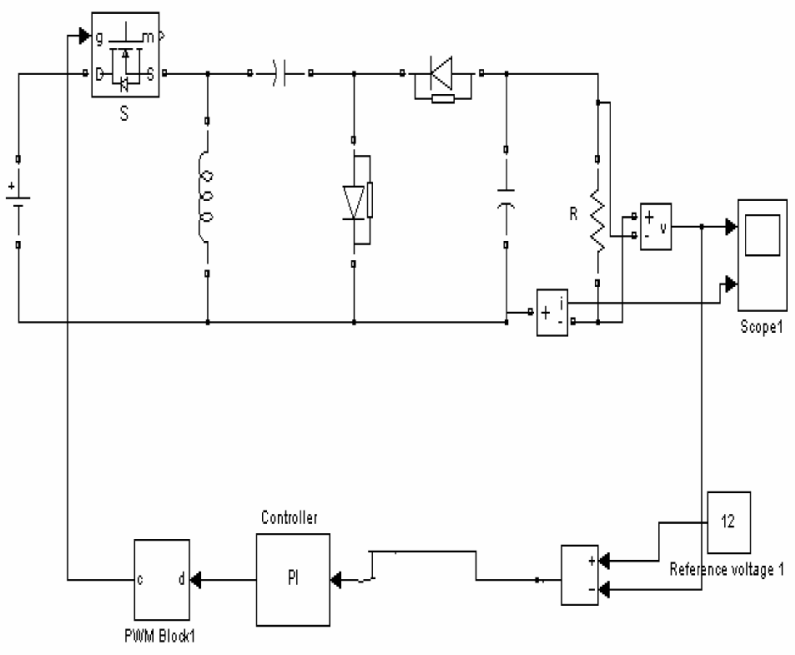

Figure 5. Simulation Model using PI Controller.

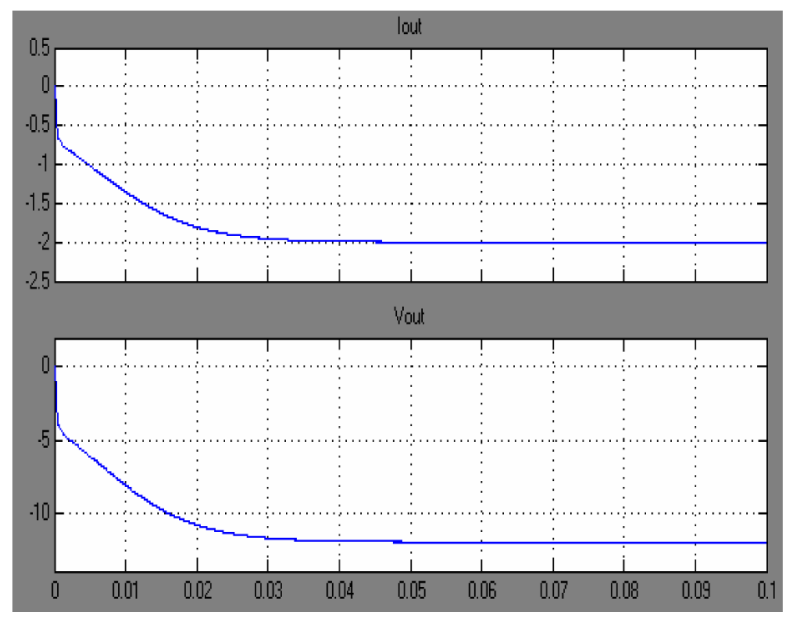

Figure 6. Output Voltage and Output Current $\left(\mathrm{V}_{\text {out }}=-12 \mathrm{~V}\right)$. improved by giving feedback to the converter to overcome the disturbances. The combination of proportional and integral terms is important to increase the speed of the response and also to eliminate the steady state error. The Input Voltage is $5 \mathrm{~V}$, reference voltage is $12 \mathrm{~V}$ and the Figure 7 and Table 1 show the voltage ripple waveform and the results of voltage ripples observed in the output waveform using PI controller. From the waveform and tabulation it is clear that the PI controller produces ripples in the range of $3 \mathrm{mV}$. But the output voltage varies from $11.998 \mathrm{~V}$ to $12.001 \mathrm{~V}$ which oscillates below the reference voltage range. Hence we are going for FLC results.

Figure 8 and Table 2 show the current ripple waveform and results of current ripples observed in the output current waveform using PI controller. From the waveform and tabulation of current ripple it is clear that the PI controller produces ripples in the range of $1.76 \mathrm{~mA}$ which is of high value when compared with the fuzzy logic controller.

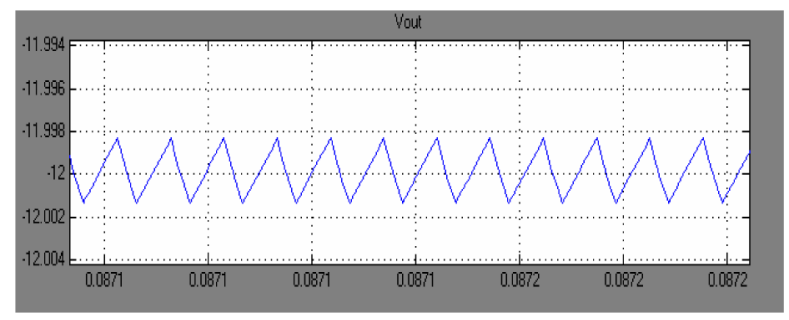

Figure 7. Voltage ripples in PI Controller.

Table 1. Voltage Ripples in PI Controller

\begin{tabular}{cc}
\hline$\Delta \mathrm{V}$ & $\mathrm{V}_{2}-\mathrm{V}_{1}$ \\
$\Delta \mathrm{V}$ & $12.001-11.998$ \\
$\Delta \mathrm{V}$ & $3 \mathrm{mV}$ \\
\hline
\end{tabular}

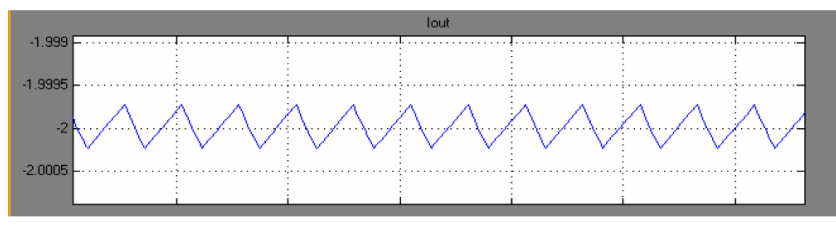

Figure 8. Current ripples in PI Controller.

Table 2. Current Ripples in PI Controller

\begin{tabular}{cc}
\hline$\Delta \mathrm{I}$ & $\mathrm{I}_{2}-\mathrm{I}_{1}$ \\
$\Delta \mathrm{I}$ & $2.0015-1.99974$ \\
$\Delta \mathrm{I}$ & $1.76 \mathrm{~mA}$ \\
\hline
\end{tabular}




\section{Closed Loop Negative KY Boost Converter using Proportional Integral Derivative Controller}

A proportional controller $(\mathrm{Kp})$ will have the effect of reducing the rise time and will reduce, but never eliminate, the steady-state error. An integral control (Ki) will have the effect of eliminating the steady-state error, but it may make the transient response worse. A derivative control (Kd) will have the effect of increasing the stability of the system, reducing the overshoot, and improving the transient response. Defining $\mathrm{u}(\mathrm{t})$ as the controller output, the final form of the PID algorithm is:

$$
u(t)=M V(t)=\operatorname{Kpe}(t)+\operatorname{Ki} \int e(\tau) d \tau+K d \frac{d e(t)}{d t}
$$

where

Kp: Proportional gain, a tuning parameter

Ki: Integral gain, a tuning parameter

$\mathrm{Kd}$ : Derivative gain, a tuning parameter

e: Error $=$ SP-PV

t: Time or instantaneous time (the present)

$\tau$ : Variable of integration; takes on values from time 0 to $t$

The simulink model of PID controller is shown in Figure 9 and it is constructed for the Negative output KY boost converter and its performances are analyzed for the voltage, current and power waveforms.

The output voltage and current waveforms are shown in Figure 10. When compared with PI, a PID controller reduces the overshoot, increases the stability and improves the transient response of the system. Here the applied input voltage is $5 \mathrm{~V}$, the reference voltage is $12 \mathrm{~V}$ and the actual output voltage obtained is $12.02 \mathrm{~V}$ and its

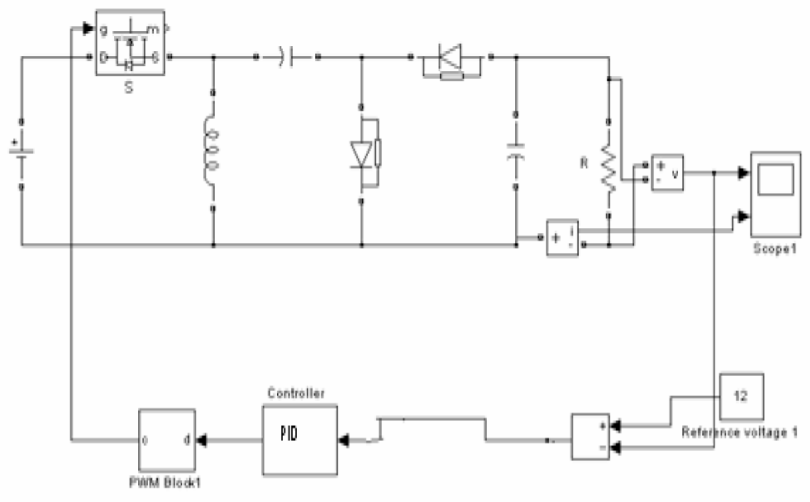

Figure 9. Simulation Model using PID Controller. settling time is $0.02 \mathrm{Sec}$. From the voltage waveform it can be notified that the introduction of PID controller further reduces the steady state error with the fast settling time.

Figure 11 and Table 3 show the voltage ripple waveform and the results of voltage ripples observed in the output waveform using PID controller. From the waveform and tabulation it is clear that the voltage ripples are in the range of $103 \mathrm{mV}$ which is very high when compared with PI and FLC controllers.

Figures 12 and Table 4 show the current ripple waveform and the results of current ripples observed in the

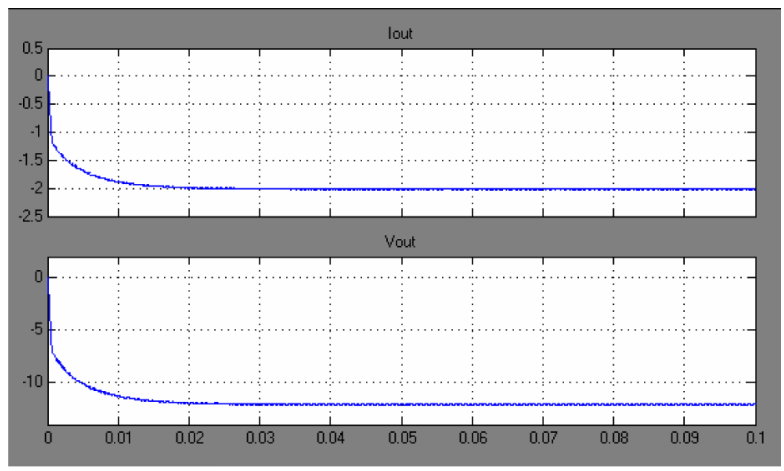

Figure 10. Output Voltage and Output Current.

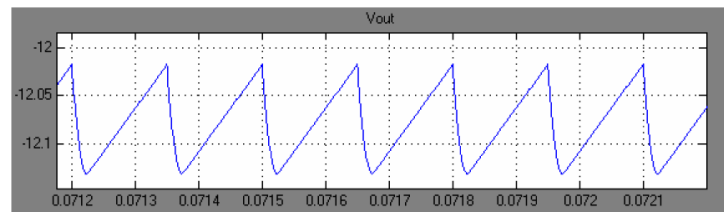

Figure 11. Voltage ripples in PID Controller.

Table 3. Voltage Ripples in PID Controller

\begin{tabular}{cc}
$\Delta \mathrm{V}$ & $\mathrm{V}_{2}-\mathrm{V}_{1}$ \\
$\Delta \mathrm{V}$ & $12.123-12.02$ \\
$\Delta \mathrm{V}$ & $103 \mathrm{mV}$ \\
\hline
\end{tabular}

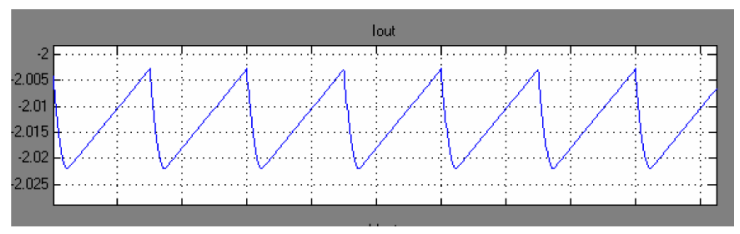

Figure 12. Current ripples in PID Controller.

Table 4. Current Ripples in PID Controller

\begin{tabular}{cc}
$\Delta \mathrm{I}$ & $\mathrm{I}_{2}-\mathrm{I}_{1}$ \\
$\Delta \mathrm{I}$ & $2.022-2.0055$ \\
$\Delta \mathrm{I}$ & $16.5 \mathrm{~mA}$ \\
\hline
\end{tabular}


output current waveform using PID controller. From the above waveform and tabulation of current ripples it is clear that the ripples produced by PID controller are in the range of $16.5 \mathrm{~mA}$ which is very high when compared with that of PI controller.

\section{Voltage Control using Fuzzy Logic Controller}

\subsection{Introduction about Fuzzy Logic Controller}

Advanced techniques have been developed for obtaining practical control systems. In those techniques fuzzy logic has been practiced as an extraordinary control technique. In recent days, fuzzy logic controller has been extensively adopted for industrial controls in order to overcome the complexity in applying the conventional control design techniques.

The fuzzy logic controller is designed based on the rules set by linguistic variables. The voltage error $(\mathrm{V})$ and voltage error variation $(\Delta \mathrm{V})$ are given as input variables to the fuzzy controller and the output from fuzzy is measured as frequency variation $(\Delta \mathrm{f})$ and given as input to the switch to attain the reference voltage.

The Input to FLC is defined as $\mathrm{e}=\mathrm{V}_{\text {ref }}-\mathrm{V}_{\text {out }}$ where, $\mathrm{V}_{\text {out }}$ is definite output voltage of Negative output KY boost converter at the $\mathrm{n}^{\text {th }}$ sampling time, $\mathrm{V}_{\text {ref }}$ is reference output voltage. The output of the Fuzzy is change in duty ratio $(\mathrm{du}(\mathrm{n}))$. Duty ratio $\mathrm{d}(\mathrm{n})$, at the $\mathrm{n}^{\text {th }}$ sampling time, is defined as

$$
\mathrm{d}(\mathrm{n})=\mathrm{d}(\mathrm{n}-1)+\mathrm{du}(\mathrm{n})
$$

Then it is send through the PWM out to Negative output KY boost converter to generate desired switching action $^{2}$.

The designed fuzzy rules used in this research are tabulated in Table 5. Recent research area has developed controller models based on fuzzy logic, hybrid fuzzy and neural techniques ${ }^{2-4}$.

The input ranges considered here for Voltage error and Voltage error variation are respectively between -10 to +10 and -0.5 to +0.5 respectively (Figure 13 ). For these input ranges the output is obtained between 0.4445 to 0.8445 .Member function 1 ( $\mathrm{mfl}$ ) Value is 0.445 and Member function2 ( $\mathrm{mf} 2$ ) value is 0.8445 (Figures 14 and 15).
Table 5. FLC rule table

\begin{tabular}{cccccc}
\hline $\mathrm{V} / \Delta \mathrm{V}$ & $\mathrm{NB}$ & $\mathrm{NS}$ & $\mathrm{Z}$ & $\mathrm{PS}$ & $\mathrm{PB}$ \\
$\mathrm{NB}$ & $\mathrm{NB}$ & $\mathrm{NB}$ & $\mathrm{NS}$ & $\mathrm{NS}$ & $\mathrm{Z}$ \\
$\mathrm{NS}$ & $\mathrm{NB}$ & $\mathrm{NS}$ & $\mathrm{NS}$ & $\mathrm{Z}$ & $\mathrm{PS}$ \\
$\mathrm{Z}$ & $\mathrm{NS}$ & $\mathrm{NS}$ & $\mathrm{Z}$ & $\mathrm{PS}$ & $\mathrm{PS}$ \\
$\mathrm{PS}$ & $\mathrm{NS}$ & $\mathrm{Z}$ & $\mathrm{PS}$ & $\mathrm{PS}$ & $\mathrm{PB}$ \\
$\mathrm{PB}$ & $\mathrm{Z}$ & $\mathrm{PS}$ & $\mathrm{PB}$ \\
\hline
\end{tabular}

Figure 13. Input variables of fuzzy system.

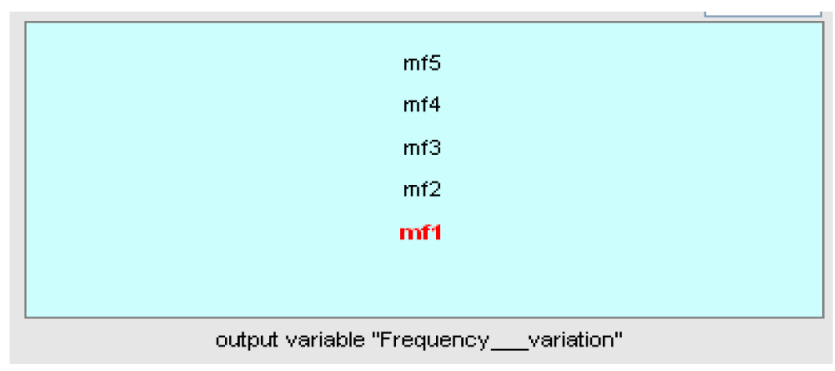

Figure 14. Output variables of fuzzy system.

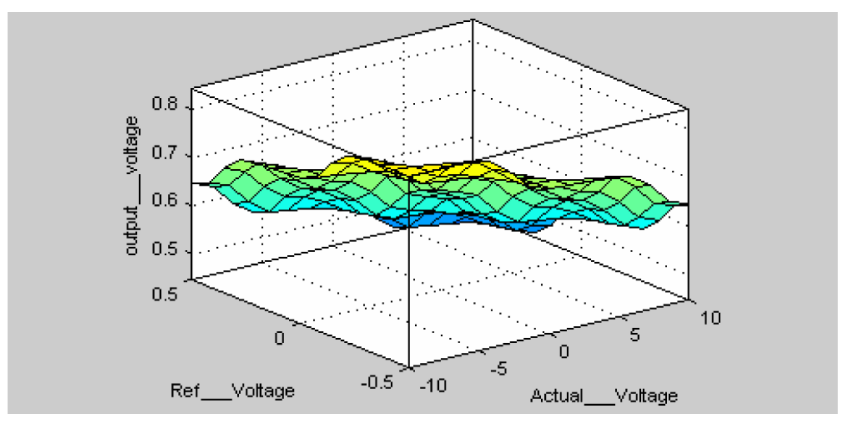

Figure 15. Surface view. 
Frequency variation has five membership functions vary between the interval .The memberships functions are described as follows: "NB" is Negative and big; "NS" is Negative and small; " $Z$ " is Zero; "PS" is Positive and small; "PB" is Positive and Big; "PL" is Positive and Large. The linguistic rules used in FL controller (Figure 16) are shown by the linguistic rules of fuzzy system can be explained using examples:

- If (Voltage error is NB) and (change in voltage error is $\mathrm{NB}$ ), Then (frequency variation is NB)

- If (voltage error is $Z$ ) and (change in voltage error is $\mathrm{NB}$ ), Then (frequency variation is NS)

- If (voltage error is $\mathrm{PB}$ ) and (change in voltage error is $\mathrm{NB}$ ), Then (frequency variation is $\mathrm{Z}$ ) and so on.

\subsection{Closed Loop Negative KY Boost Converter using Fuzzy Logic Controller}

The simulink model of proposed fuzzy logic controller is shown in Figure 17 and is designed for the Negative output KY boost converter and its performances are observed by the voltage, current and power waveforms.

The output voltage and current waveforms are shown in Figure 18. PID controller cannot be applied with the systems which have a fast change of parameters, because it would require the change of PID constants in the time but the Fuzzy controller can be applied for studying different ranges of input parameters with respective outputs.
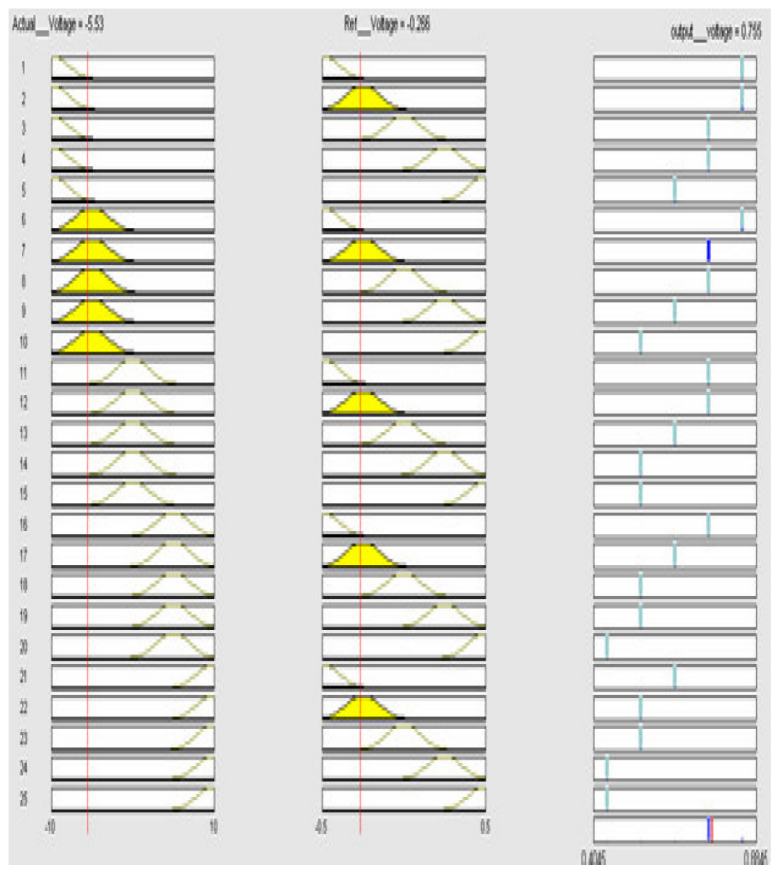

Figure 16. Fuzzy rule viewer.
The Input Voltage is $5 \mathrm{~V}$, Reference voltage is $12 \mathrm{~V}$, the actual output voltage obtained is $12.05 \mathrm{~V}$ and the settling time is $0.015 \mathrm{Sec}$. From the voltage waveform, it can be notified that the fuzzy logic controller reduces the voltage regulation and achieved with perfect speed tracking without overshoot ${ }^{5}$.

Figure 19 and Table 6 shows the result of voltage ripples observed in the output waveform using fuzzy logic

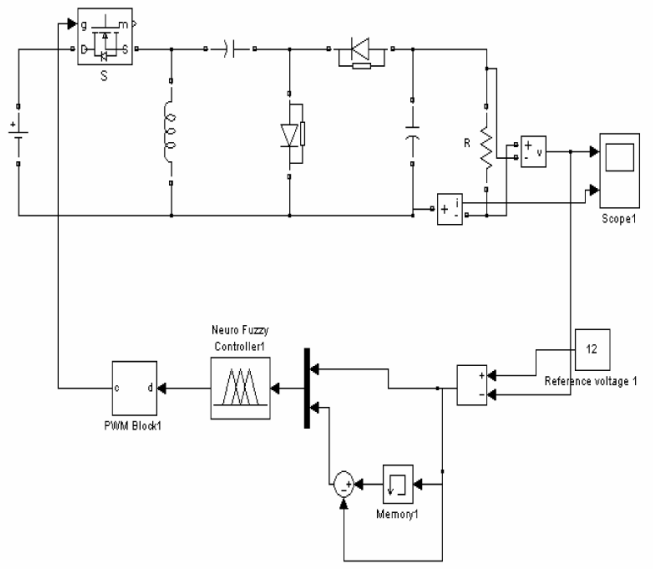

Figure 17. Simulation Model using Fuzzy logic controller.

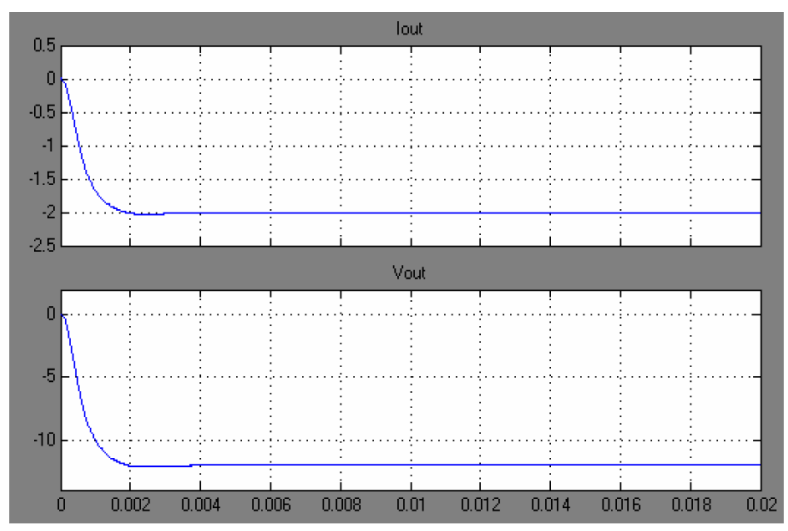

Figure 18. Output voltage and output current.

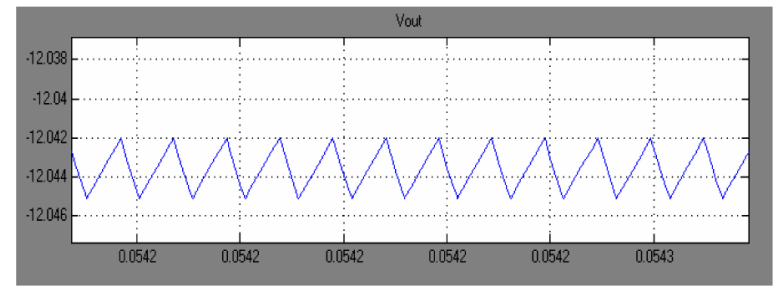

Figure 19. Voltage ripples in fuzzy logic controller.

Table 6. Voltage Ripples in Fuzzy Logic Controller

\begin{tabular}{cc}
\hline$\Delta \mathrm{V}$ & $\mathrm{V}_{2}-\mathrm{V}_{1}$ \\
$\Delta \mathrm{V}$ & $12.045-12.042$ \\
$\Delta \mathrm{V}$ & $3 \mathrm{mV}$ \\
\hline
\end{tabular}


controller. From the results it is noted that the fuzzy logic controller scale down the voltage ripples from $103 \mathrm{mV}$ of PID output to $3 \mathrm{mV}$. Also the ripple output varies above the reference voltage range when compared with the PI controller.

Figure 20 and Table 7 show the current ripple waveform and the results of current ripples observed in the output current waveform using fuzzy logic controller. From the above waveforms and tabulation of current ripples it is clear that the fuzzy logic controller has the lowest current ripples i.e. it is reduced from $16.5 \mathrm{~mA}$ to $0.5 \mathrm{~mA}$ when compared with PI and PID controllers.

\subsection{Closed Loop Negative KY Boost Converter using Fuzzy Logic Controller with Sudden Disturbance}

The performance of various controllers are analyzed in III, IV and V section, in this section the response of fuzzy logic controller is analyzed by applying a sudden disturbance to the load (Figure 21).

The simulink model is designed for the Negative output KY boost converter using Fuzzy controller with sudden disturbance and their corresponding output waveform is shown in Figures $22 \&$ 23.The input Voltage is $5 \mathrm{~V}$ and the disturbance of $0.25 \mathrm{~V}$ is applied after $0.05 \mathrm{Sec}$. The Reference voltage is $12 \mathrm{~V}$, the actual voltage obtained is $13.24 \mathrm{~V}$ and the voltage is settled after $0.05 \mathrm{Sec}$.Even under the disturbance condition the FLC suits well.

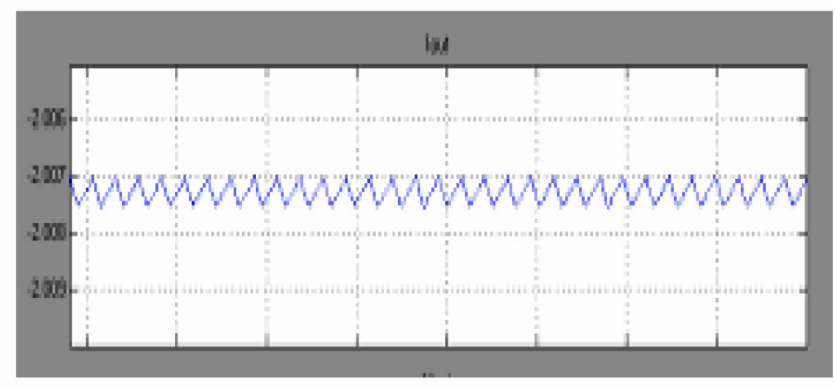

Figure 20. Current ripples in fuzzy logic controller.

Table 7. Current ripples in fuzzy logic controller

$\begin{array}{cc}\Delta \mathrm{I} & \mathrm{I}_{2}-\mathrm{I}_{1} \\ \Delta \mathrm{I} & 2.0075-2.007 \\ \Delta \mathrm{I} & 0.5 \mathrm{~mA}\end{array}$

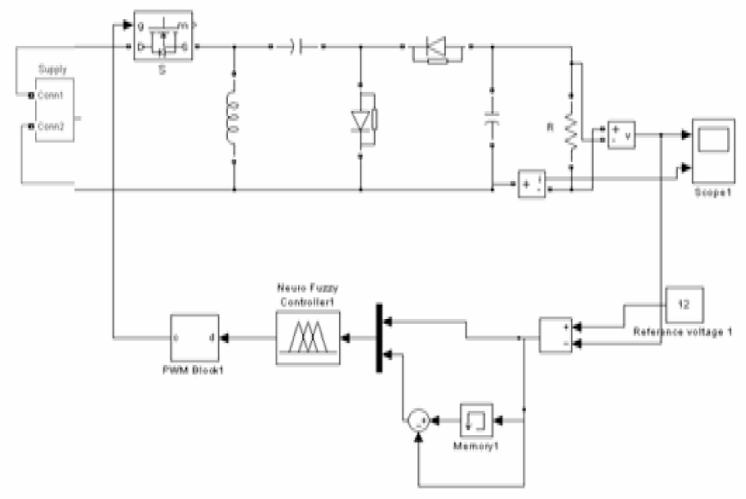

Figure 21. Simulation model using fuzzy logic controller with sudden disturbance.

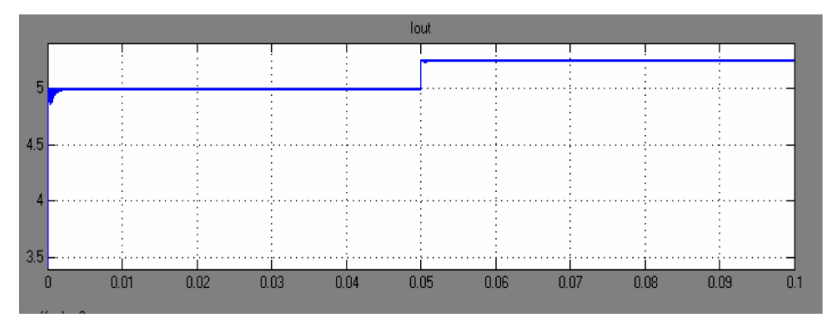

Figure 22. Input voltage.

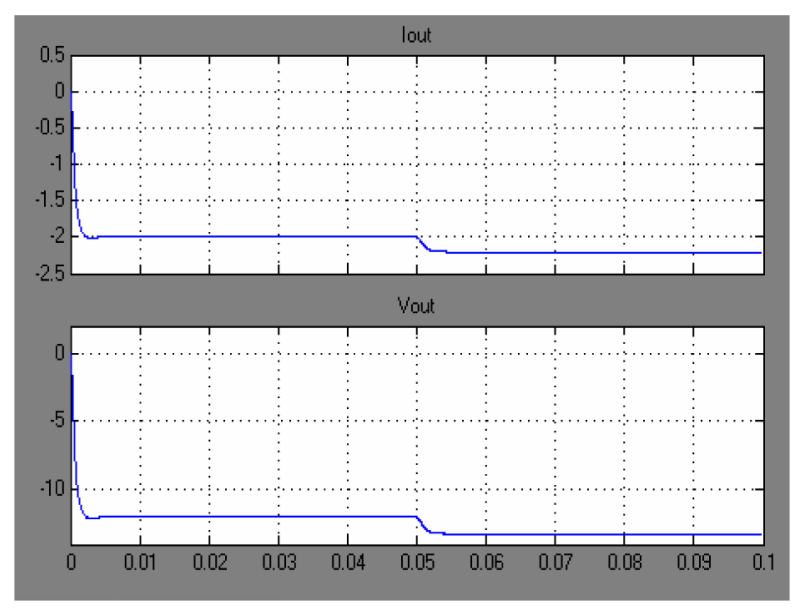

Figure 23. Output Voltage and Output Current.

\section{Comparisons and Results}

\subsection{Various Parameters Comparisons}

Table 8 represents the overall comparison for output voltages and settling time for PI, PID and Fuzzy Logic Controllers. From the results it is shown that the fuzzy controller settles actively compared to the other controllers.

Table 9 shows the voltage ripples and current ripples for PI, PID and Fuzzy Logic Controllers. From the results 
Table 8. Comparison of voltage controllers

\begin{tabular}{lcc}
\hline Controller & $\begin{array}{c}\text { Output Voltage } \\
\text { (Volts) }\end{array}$ & $\begin{array}{c}\text { Settling Time } \\
(\mathrm{sec})\end{array}$ \\
\hline PI & 12 & 0.03 \\
PID & 12.02 & 0.02 \\
FLC & 12.05 & 0.015 \\
\hline
\end{tabular}

Table 9. Comparison of ripples

\begin{tabular}{lcc}
\hline Controller & $\begin{array}{c}\Delta \mathrm{V}(\text { Voltage } \\
\text { ripples mV) }\end{array}$ & $\begin{array}{c}\Delta \mathrm{I}(\text { Current } \\
\text { ripples mA })\end{array}$ \\
\hline PI & 3 & 1.76 \\
PID & 103 & 16.5 \\
FLC & 3 & 0.5 \\
\hline
\end{tabular}

it is proved that the fuzzy controller produces lesser ripples compared to the other controllers.

\subsection{Load Variation of Output Power Waveform}

Figure 24 shows the output power waveform of PI controller by varying the load values. Here the load used is of resistive load and for different load values $(\mathrm{R}=2 \Omega-30 \Omega)$, the output power is calculated. The max power obtained is only $36 \mathrm{~W}$. From the waveform it is clear that the waveform is linear with increase in the load values.

Figure 25 shows the output power waveform of PID controller by varying the load values. Here the load used is of resistive load and for different load values $(\mathrm{R}=$ $2 \Omega-30 \Omega$ ), the output power is calculated. The max power obtained is $28.11 \mathrm{~W}$. From the waveform it is clear that the waveform is non-linear with increase in the load values when compared with PI power curve.

Figure 26 shows the output power waveform of fuzzy logic controller by varying the load values. Here the load used is of resistive load and for different load values $(\mathrm{R}=$ $2 \Omega-30 \Omega$ ), the output power is calculated. The max power obtained is 59.21

W. From the results and waveform it is clear that the power is maximum while using fuzzy logic controller when compared with PI and PID controllers.

\subsection{Line Regulation of Output Power Waveform}

Figure 27 shows the output power waveform of PI controller by varying the line voltages. Here the line

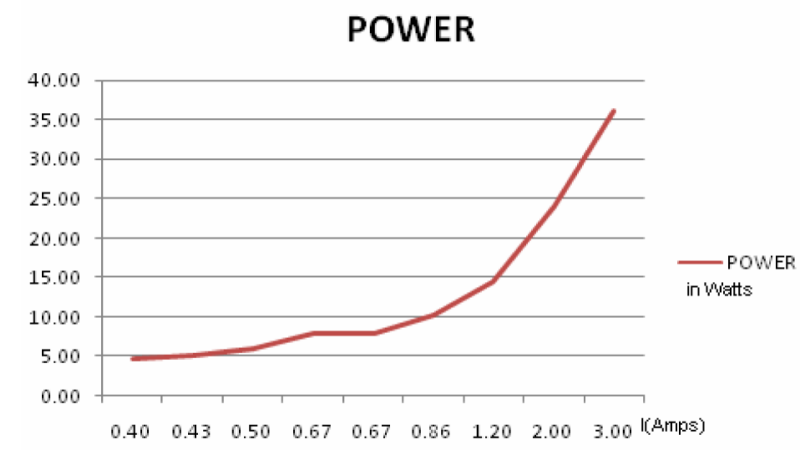

Figure 24. PI Controller output power waveform under load resistance variations.

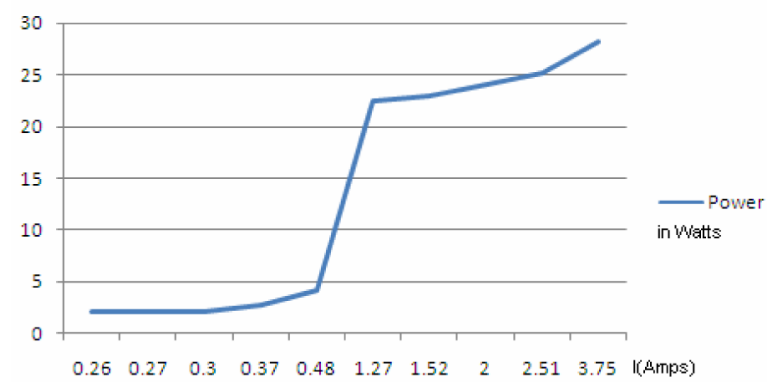

Figure 25. PID Controller output power waveform under load resistance variations.

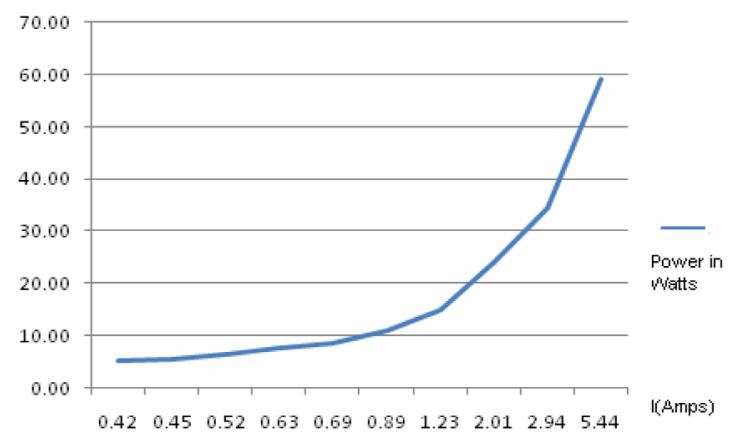

Figure 26. FLC Controller output power waveform under load resistance variations.

POWER

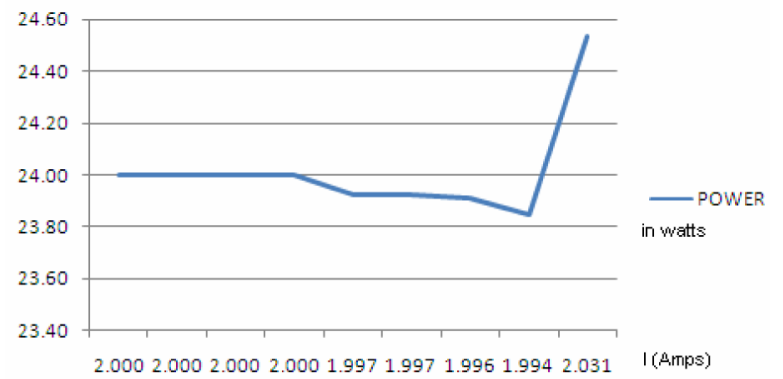

Figure 27. PI Controller output power waveform under input Voltage variations. 
voltage is varied with different values (Vin $=5 \mathrm{~V}-20 \mathrm{~V}$ ), and the respective output power is calculated. The max power obtained is $24.53 \mathrm{~W}$. From the power and value it is clear that the power generated is of lesser value and also the power varies non-linearly with the line voltage values.

Figure 28 shows the output power waveform of PID controller by varying the line voltages. Here the line voltage is varied with different values $\left(\mathrm{V}_{\text {in }}=5 \mathrm{~V}-20 \mathrm{~V}\right)$, and the respective output power is calculated. The max power obtained is $474.78 \mathrm{~W}$. From the value it is understood that the power obtained is of higher value when compared with the PI controller and also the power varies linearly with the line voltage values.

Figure 29 shows the output power waveform of fuzzy logic controller by varying the line values. Here the line voltage is varied with different values $\left(\mathrm{V}_{\text {in }}=\right.$ $5 \mathrm{~V}-20 \mathrm{~V}$ ), and the respective output power is calculated. The max power obtained is $987.65 \mathrm{~W}$. From the value it is understood that the power obtained is of higher value when compared with the PI and PID controllers

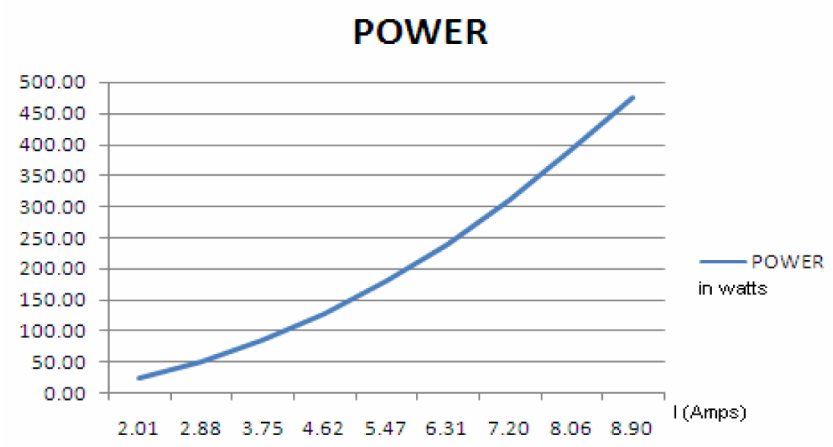

Figure 28. PID Controller output power waveform under input voltage variations.

\section{POWER}

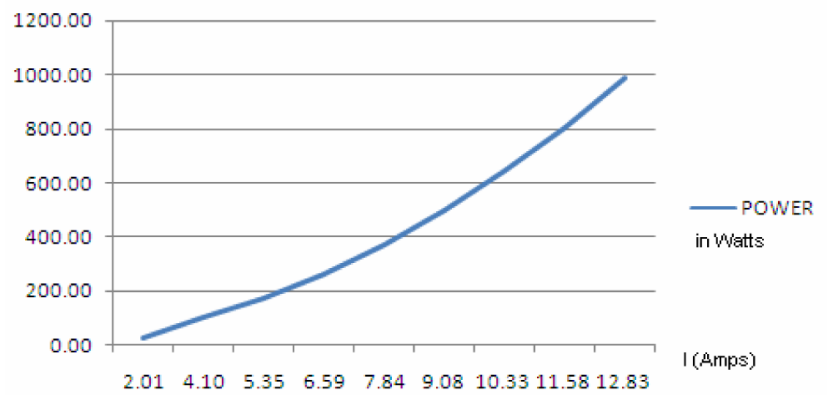

Figure 29. FLC Controller output power waveform under input voltage variations. and also the power varies linearly with the line voltage values.

Table 10 represent the overall comparison for power output using load regulation and line regulation for PI, PID and Fuzzy Logic Controllers. From the results it is proved that the fuzzy controller generates maximum power when compared to other controllers.

Table 11 shows different design parameters used in the circuit.

Figure 30 shows the hardware image of Negative output KY boost converter. It consists of Input transformer, Dual RPS, Resistive load, Microcontroller unit, gate driver circuit for giving pulse to the MOSFET and voltage sensing and signal conditioner unit.

Figure 31 shows the hardware implementation diagram for negative $\mathrm{KY}$ boost converter. It consists of power supply circuit, control circuit and power circuit. As mentioned earlier the power supply circuit consists of a DC supply ranging from $\pm 5 \mathrm{v}$ to \pm 12 . The control circuit consists of PIC microcontroller with model no.PIC16F877A. It also contains a gate driver circuit which feeds the MOSFET that is used in the power circuit. The power circuit consists of one MOSFET

\begin{tabular}{lcc} 
Table. 10 & Comparisons of Powers \\
\hline Controller & $\begin{array}{c}\text { Max Power (Load } \\
\text { Regulation) }\end{array}$ & $\begin{array}{c}\text { Max Power (Line } \\
\text { Regulation) }\end{array}$ \\
\hline PI & 36 & 24.53 \\
PID & 28.11 & 474.28 \\
FLC & 59.21 & 987.65 \\
\hline
\end{tabular}

\begin{tabular}{|c|c|}
\hline Parameters & Values \\
\hline$V_{\text {in }}$ & $5 \mathrm{~V}$ \\
\hline$V_{\text {out }}$ & $-12 \mathrm{~V}$ \\
\hline $\mathrm{R}_{\mathrm{o}}$ & $2 \Omega$ \\
\hline$P_{\text {out }}$ & 24Watts \\
\hline $\mathrm{P}_{\min }$ & 3.6Watts \\
\hline $\mathrm{F}_{s}$ & $195 \mathrm{KHZ}$ \\
\hline $\begin{array}{ll}\text { PI } & \mathrm{K}_{\mathrm{p}} \\
& \mathrm{K}_{\mathrm{i}}\end{array}$ & $\begin{array}{c}0.02 \\
7\end{array}$ \\
\hline $\begin{array}{ll}\text { PID } & \mathrm{K}_{\mathrm{p}} \\
& \mathrm{K}_{\mathrm{i}} \\
& \mathrm{K}_{\mathrm{d}}\end{array}$ & $\begin{array}{c}0.045 \\
2 \\
0.001\end{array}$ \\
\hline $\mathrm{C}_{\mathrm{b}}$ & $1000 \mu \mathrm{F}$ \\
\hline $\mathrm{C}_{\mathrm{o}}$ & $2200 \mu \mathrm{F}$ \\
\hline L & $10 \mu \mathrm{H}$ \\
\hline
\end{tabular}




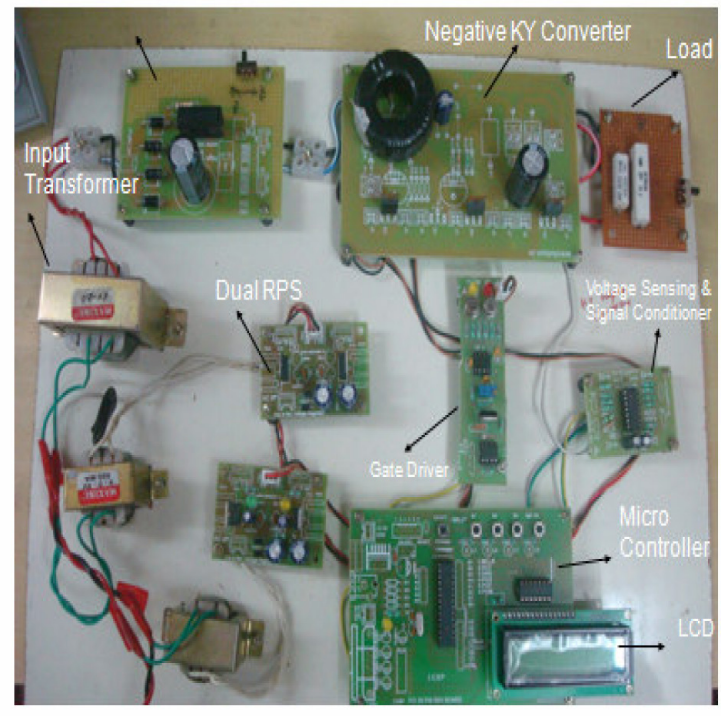

Figure 30. Hardware image of Negative output KY boost converter.
(IRF 840) which acts as a switch for the negative KY boost converter.

\section{Conclusion}

The Negative KY boost converter performance was analyzed and the simulink model has been solved using MATLAB/ simulink environment. The closed loop control of Negative KY boost converter has been studied and operated for conventional based PI \& PID Controller and Neuro based on fuzzy logic controller. The simulation results show that Fuzzy Logic Controller achieves better than PI \& PID controller. This paper implements a fuzzy logic controller to ensure excellent reference tracking of Negative KY boost converter. The fuzzy logic controller enhances the voltage regulation and it gives a perfect voltage tracking without overshoot.

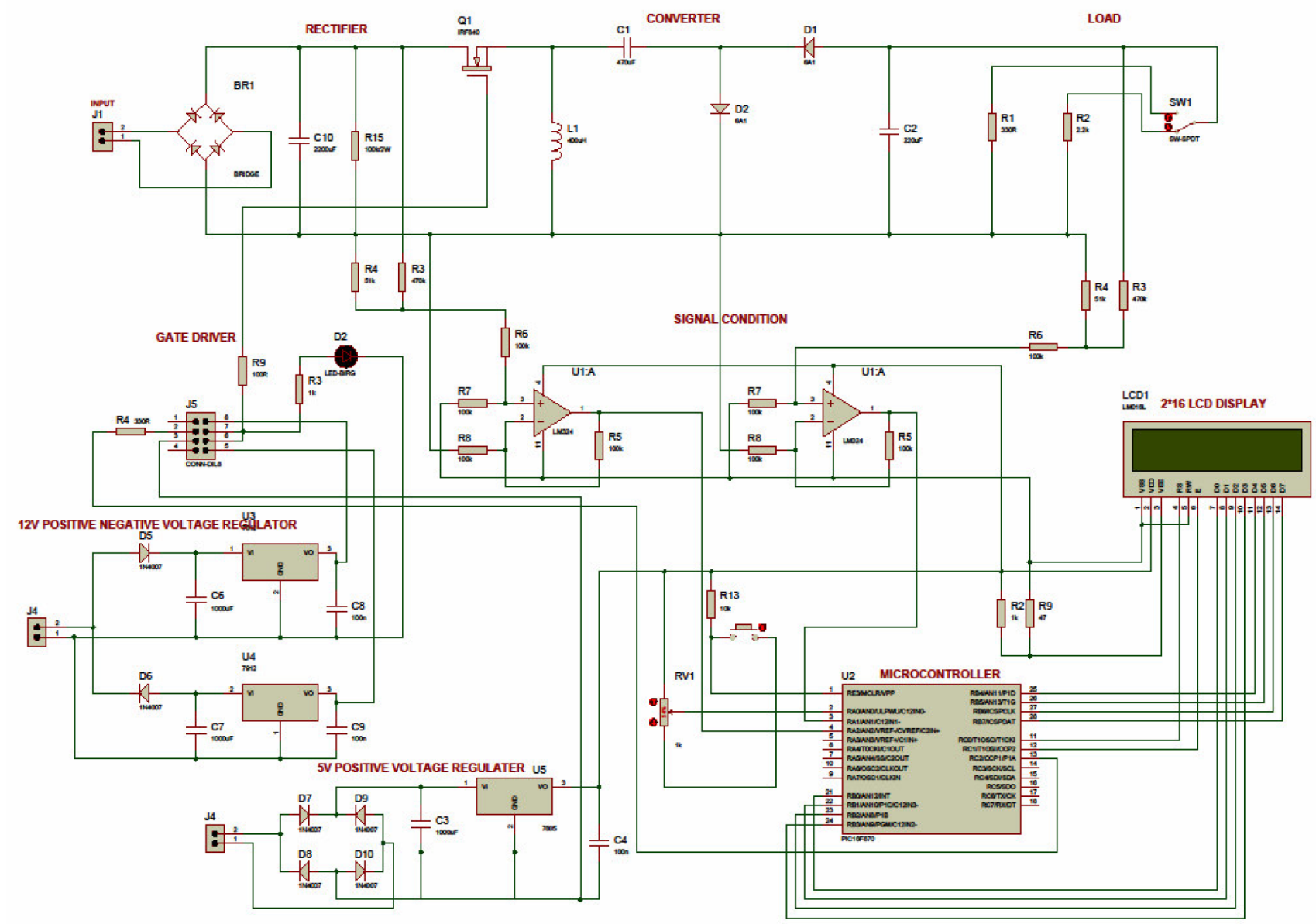

Figure 31. Hardware Implementation diagram of negative output ky boost converter. 


\section{References}

1. Hwu KI, Tu WC, Chen YH. A novel negative-output KY boost converter. Industrial Electronics (ISIE). 2009; 272-74.

2. Luo FL, Ye H. Negative output super-lift converters. IEEE Trans. Power Electron. 2003; 18(5):1113-21.

3. Adaptive fuzzy logic controller for DC-DC converters Cetin Elmas a, Omer Deperlioglu b, *, Hasan Huseyin
Sayan, Department of Electric, Faculty of Technical Education, University of Gazi, 06500 Ankara, Turkey; 2007.

4. Giral R, Arango E, Calvente J, Martinez-Salamero L. Inherent DCM operation of the asymmetrical interleaved dual buck-boost. Proc IEEE IECON Conf.; 2002. p. 129-34.

5. Hwu KI, Yau YT. A KY Boost Converter. IEEE Transaction. 2009; 25(11):2699-703. 